\title{
Anthropometric changes and their effects on cardiometabolic risk factors in rural populations in Brazil
}

\author{
Mudanças antropométricas e seus efeitos sobre os fatores de risco \\ cardiometabólicos em populações rurais do Brasil
}

Tatiane Géa-Horta ${ }^{1}$

Mark Anthony Beinner ${ }^{1}$

Andrea Gazzinelli ${ }^{1}$

Mariana Santos Felisbino Mendes ${ }^{1}$

Gustavo Velasquez-Melendez ${ }^{1}$

${ }^{1}$ Escola de Enfermagem, Universidade Federal de Minas Gerais. Av. Alfredo Balena 190, Santa Efigênia. 30130-100 Belo Horizonte MG Brasil. guveme@ufmg.br

\begin{abstract}
This article aims to evaluate associations between anthropometric changes in five years with lipid and blood pressure levels in Brazilian rural population. This longitudinal study evaluated 387 individuals aged 18 to 75 residents of two rural communities. Demographic, lifestyle, anthropometric, biochemical and hemodynamic characteristics were assessed in 2004 and repeated in 2009. Multivariate linear regression was used. Positive change in BMI was associated with increased diastolic blood pressure (DBP) $(\beta=$ 0.07; 95\% CI: 0.03-0.11), low-density lipoprotein ( $L D L-C$ ) (increase of $0.01 \%$ to $10 \%: \beta=0.08$; 95\%CI: $0.02-0.14$, more than $10 \%$ increase: $\beta$ $=0.09$; 95\%CI: 0.01-0.16) and low density lipoprotein/high density lipoprotein cholesterol ratio ( $L D L-C / H D L-C$ ) (increase of $0.01 \%$ to $10 \%: \beta=$ 0.15; 95\% CI: $0.06-0.25$, more than $10 \%$ increase: $\beta=0.14 ;$ 95\%CI: 0.02-0.25). Our results showed no association between positive changes in WC and lipid levels increase, only with blood pressure levels increase (SBP: $\beta=0.06$; CI95\%:0.020.10; DBP: $\beta=0.09$; CI95\%: 0.04;0.13). Positive changes in BMI are independent predictors of increased lipid and blood pressure levels and positive changes in WC of increased blood pressure. Key words Anthropometry, Cardiovascular diseases, Rural population, Body Mass Index, Waist Circumference
\end{abstract}

Resumo O objetivo deste artigo foi avaliar associação entre as mudanças antropométricas, em cinco anos de estudo, com os niveis lipídicos e pressóricos em populações rurais brasileiras. Estudo longitudinal, que avaliou 387 individuos, entre 18 e 75 anos, residentes em duas comunidades rurais. Características demográficas, de estilo de vida, antropométricas, bioquímicas e hemodinâmicas foram coletadas em 2004 e repetidas em 2009. Utilizou-se a regressão linear. Mudanças positivas do IMC foram associadas com aumento da pressão arterial diastólica (PAD) $(\beta=$ 0,07; IC95\%: 0,03-0,11), lipoproteína de baixa densidade ( $L D L-C$ ) (aumento de 0,01\% a 10\%: $\beta=0,08$; IC95\%: 0,02-0,14; aumento de mais de 10\%: $\beta=0,09$; IC95\%: 0,01-0,16) e razão lipoproteina de baixa densidade/lipoproteína de alta densidade (LDL-C/HDL-C) (aumento de 0,01 a 10\%: $\beta=0,15$; IC95\%: 0,06-0,25; aumento de mais de $10 \% \beta=0,14$; IC95\%: 0,02-0,25). Não se observou associação entre mudanças positivas na CC e aumento de níveis lipídicos, apenas com aumento da pressão arterial (PAS: $\beta=0,06$; IC95\%: 0,02-0,10; PAD: $\beta=0,09$; IC95\%: 0,040,13). Mudanças positivas no IMC são preditoras independentes para aumento de niveis lipidicos e pressóricos e mudanças positivas na CC para aumento de níveis pressóricos.

Palavras-chave Antropometria, Doenças cardiovasculares, População rural, Índice de Massa Corporal, Circunferência da Cintura 


\section{Introduction}

Advances in technology and constant changes in eating habits are responsible for reducing energy expenditure and, therefore, the leading causes of weight gain in populations. Recent estimates have predict that by 2025 , about three billion people worldwide will experience excess weight gain and another 700 million will suffer from obesity $^{1,2}$.

Thus, overweight and obese individuals share a greater risk of developing combined effects of dyslipidemia and hypertension, important risk factors of cardiovascular diseases (CVD). A greater effect is also observed due to increased waist circumference (WC) $)^{3-6}$. Moreover, cardiovascular diseases are responsible for a large share of the reported morbidity and mortality rates, along with higher incidence of hospitalizations, which altogether have resulted in an enormous socioeconomic burden in Brazil'.

Data from population-based surveys conducted in the last 35 years have shown an important rise in overweight rates among Brazilian adults from $18.5 \%$ in $1974-75$ to $50.1 \%$ in 2008 09 among men and $28.7 \%$ to $48 \%$ among women during the same periods. Similarly, obesity rates have raised more than four times among men, from $2.8 \%$ to $12.5 \%$ and more than twice among women, $8 \%$ to $16.9 \%^{7}$. In the same report it was also shown an increment in the prevalence of overweight and obesity among Brazilian rural population.

Nutritional transition process and lifestyle changes have been observed in populations of metropolitan areas in Brazil since the $1970^{8}$. This phenomena has also been observed in rural areas, where major demographic, socioeconomic and epidemiological changes, results from forced modernization in the field and biased and exclusive development has caused changes in lifestyle profile of rural populations ${ }^{9}$, which has lead to increased lipid, glucose and blood levels, overweight and obesity ${ }^{10,11}$.

In addition, rural populations suffer from health problems to a greater extent and experience disadvantages in access, supply, complexity and quality of health services compared to urban populations. Furthermore, residents of rural areas have particular characteristics such as low educational level and socioeconomic status, which reveal greater vulnerability to cardiometabolic factors, which has been reported as the main reason for absenteeism or non-performance of usual activities $^{12}$. Assessing the anthropometric indexes in specific populations is of utmost importance since the Pan American Health Organization information has supported a steady growth of individuals with overweight and obesity ${ }^{13}$.

This study will contribute to defining priorities and strategies of action on public health, considering that the presence of above-average weight is related to various diseases, specially the cardiovascular ones, independently of race, sex, age or level social. We not found in the literature studies about body mass index and waist circumference changes in the adult population in rural communities in Brazil. In this context, the present study aims to estimate the associations between anthropometric changes in five years and lipid and blood pressure levels in Brazilian rural areas.

\section{Methods}

\section{Design, location and study population}

This is a longitudinal study conducted in rural settings: Caju and Virgem das Graças communities, respectively, located in the northeast state of Minas Gerais. The baseline evaluation (phase I) occurred in 2004 and the follow-up (phase II) was carried-out in 2009. Face-to-face interview was conducted by trained nurses and nutritionists at the health center in both communities. The questionnaires included data about demographic, socio-economic, anthropometric, biochemical, lifestyle habits (smoking status and alcohol intake) and use of antihypertensive drugs. To be eligible, residents should be between the ages of 18 and 75 years, reside in the communities and present complete information in both phases of the study.

From a census conducted in 2004, a total of 272 families were registered in both communities, consisting in 1,216 participants. Considering the eligibility criteria to this study, at the end of the 2004, 594 subjects were studied. In 2009, we comprised a final sample of 387 due to dropouts such as deaths, hospitalization, moved away, absence on schedule days for the collection of blood samples and diagnosis of hypertension $(n=207)$.

We found no significant differences of socioeconomic and demographic characteristics between the studied subjects and the loss (data not shown). It is noteworthy that some individuals did not present complete data for all variables used in the analysis. At the end of the interview, subjects underwent a clinical evaluation 
which included anthropometric measurements (weight, height, waist circumference), according to protocol which follows international standard recomendations ${ }^{14}$.

\section{Anthropometric measurements}

The weight measurement was obtained by a single outlet through digital scale (Model PL 150, FILIZOLA, Brazil), as measured by the National Institute of Metrology, Standardization and Industrial Quality (Inmetro), with capacity for $180 \mathrm{~kg}$ and sensitivity of $100 \mathrm{~g}$. Participants were at the center of the scale platform, in the anatomical position, wearing light clothing and no shoes. Height was measured using a anthropometry coupled to the scale to measure up to $190 \mathrm{~cm}$. Individuals were standing in the center of scale platform, standing, looking forward, in a position to Frankfurt (lower orbital arc aligned in a horizontal plane with the pinna), barefoot and with feet together. Body mass index (BMI) was calculated according to the formula: BMI = weight $(\mathrm{kg}) /$ height $^{2}(\mathrm{~m})^{15}$.

For the waist circumference (WC) was used inelastic millimeter tape $150 \mathrm{~cm}$ long. With the individual standing and relaxed abdomen, arms extended along the body, the tape was placed at the midpoint between the iliac crest and the last rib without compressing tissues. Central fat distribution of the classification we used the cutoff points proposed ${ }^{16}$.

\section{Exposure variables}

To avoid the time dependence of BMI and WC changes were defined as percent of baseline values. The difference between the measure obtained in 2009 and the measure obtained in 2004 divided by the measure in 2004 and multiplied by $100 \%$. The participants were classified according to categories the relative decrease or increase in BMI or WC: Category 0: $-20.0 \%$ to $0.0 \%$; Category 1: 0.01 to $10.0 \%$ and Category 2 : $>10.0 \%$. Negative differences were interpreted as diminishing and positive differences as increments.

\section{Outcome variables}

Outcome variables included values of Systolic Blood Pressure (SBP), Diastolic Blood Pressure (DBP), High Density Lipoprotein-cholesterol (HDL-C), Low Density Lipoprotein-cholesterol (LDL-C), total cholesterol and LDL/HDL ratio, measured in 2009. Blood samples were drawn (5
$\mathrm{mL}$ ) from each participant after a fasting period of 8 to 12 hours. Blood samples, aliquots of serum and plasma, obtained by centrifugation, were properly prepared and stored in $1.0 \mathrm{~mL}$ eppendorf tubes stored at $-20^{\circ} \mathrm{C}$ until analysis. The concentration of total cholesterol (Chol) and triglycerides (TG) was determined using enzymatic-colorimetric methods using the Cobas Mira Plus analyzer (Roche Diagnostics, Switzerland). Concentration of HDL-C was also determined by colorimetric enzymatic assay after precipitation of LDL-C and very low density lipoprotein (VLDL-C) with phosphotungstic acid and chloride magnesium. LDL-C levels were then calculated according to the Friedewald equation: LDL-C $=$ Chol $-(\mathrm{HDL}-\mathrm{C}+\mathrm{TG} / 5)^{17}$. Blood pressure was determined by an indirect method, using a mercury sphygmomanometer and according to the recommendations of Joint National Committee (2003) at that time ${ }^{18}$. Measurements were taken three times in each subject, with an interval of 2 minutes between each measure.

\section{Demographic variables}

The age of the individuals was obtained throughout a document of identification and when the participant was not in possession of this document, age was asked to be given verbally. Regarding educational level, the participant informed the last year and a formal study level completed and the interviewer calculated the years of schooling.

\section{Lifestyle variables}

Participants were asked about their smoking habits, and then were classified as nonsmokers, smokers and former smokers. They were also asked about the number of cigarettes smoked daily. Regarding alcohol consumption, participants answered the consumption of beer, rum, wine, whiskey and other, and the frequency of use (daily, weekly, never or almost never). The variable consumption of alcohol considered the use or not of beverages, uniting the daily and weekly consumption category yes and never or almost never, not in the category.

\section{Data analysis}

We performed multivariate linear regression to investigate the associations of anthropometrics changes (2004-2009) in WC and BMI with SBP, DBP, total cholesterol, LDL-C, HDL-C and 
LDL/HDL. All dependent variables underwent logarithmic transformation. The multivariate linear models were adjusted for the following potential confounding variables: age (years), sex, educational level (years of study), smoking habit (number of cigarettes per day) and alcohol intake (daily / weekly consumption and never or almost never). Final models were evaluated by the coefficient $\left(\mathrm{R}^{2}\right)$ and $\mathrm{F}$ test analysis of variance. Residuals were evaluated according to the assumptions of normality, mean zero, constant variance, independence and unnecessary inclusion of quadratic terms. Data were processed and analyzed using Stata software, version 12.1.

\section{Ethics}

This study was approved by the Human Ethics Committee of the Universidade Federal de Minas Gerais. All participants were informed of the purpose of the study and their rights as participants. Before inclusion, subjects were asked to sign a consent form, according to guidelines of Resolution 196/1996 of the National Health Service and Helsinki declaration ${ }^{19}$.

\section{Results}

From the 387 studied participants, 185 were men (47.80\%) and 202 women (52.20\%). Mean age was 45.80 years. Most of the studied population presented very low educational level, 50.00\% with 1-4 year of schooling and $29.20 \%$ with no formal education. Additionally, most subjects reported no alcohol intake (51.20\%) or smoking habit (56.60\%). According to the nutritional classification, in 2009, $22.00 \%$ of men were overweight compared to $28.60 \%$ of women. Obesity was about five times greater in women than in men (data not shown). Hypertension was found on $38.00 \%$ of participants.

In 2009, women had significantly greater BMI (24.37 versus $\left.22.46 \mathrm{~kg} / \mathrm{m}^{2}\right)$ and lower weight values than men subjects ( 57.00 versus $61.30 \mathrm{~kg}$ ). There were no significant differences in WC, SBP or DPB according to sex. Total cholesterol and triglyceride were higher among women comparing to men, however, only HDL-C levels were statistically significant ( 53.00 versus $46.00 \mathrm{mg} / \mathrm{dl}$ ) (Table 1).

Table 1 also showed significant reductions of SBP levels (129.00 versus $126.66 \mathrm{~mm} / \mathrm{Hg}$, p-value $<0.05$ ), while significant increase was observed for total cholesterol (184.00 versus $197.50 \mathrm{mg} /$ dl, $\mathrm{p}$-value $<0.001)$, LDL-C (115.00 versus 125.00 $\mathrm{mg} / \mathrm{dl}$, $\mathrm{p}$-value $<0.001)$ and HDL-C (46.00 versus $50.00 \mathrm{mg} / \mathrm{dl}, \mathrm{p}=0.263)$.

Between 2004 and 2009, mean weight changes was of $2.40 \mathrm{~kg}$ (95\%CI: 1.91-2.89), mean BMI changes $1.02 \mathrm{~kg} / \mathrm{m}^{2}$ (95\%CI: $\left.0.82-1.22\right)$ and mean WC changes $2.53 \mathrm{~cm}$ (95\%CI: 1.93-3.13) (Table 2).

After multivariate linear regression models, participants who had positive changes of BMI between 2004 and 2009 showed significant increased levels of LDL-C (increase of $0.01 \%$ to $10 \%: \beta=0.08$; $95 \%$ CI: $0.02-0.14$; more than $10 \%$ increase: $\beta=0.09$; 95\%CI: $0.01-0.16)$ and LDL/ HDL ratio (increase of $0.01 \%$ to $10 \%$ : $\beta=0.15$; 95\%CI: $0.06-0.25$, more than $10 \%$ increase: $\beta=$ 0.14; 95\%CI: 0.02-0.25), when compared with those who lost BMI units (Table 3). Only participants who had positive changes of BMI (more than $10 \%$ increase) showed significant increased levels of DBP ( $\beta=0.07$; 95\%CI: 0.03-0.11) (Table $4)$. These associations remained significant after adjusting for age, sex, educational level, smoking habit and alcohol intake. No significant association was found between BMI changes and higher density lipoprotein-cholesterol (HDL), total cholesterol and SBP levels.

The present study found no association between changes in waist circumference and lipid levels (Table 3) and also observed that participants who presented more than $10 \%$ increase in WC had SBP ( $\beta=0.06$; CI95\%:0.02-0.10) and DBP ( $\beta=0.09$; CI95\%: 0.04;0.13) increase, when compared to those whose WC decreased (Table 4). These associations remained significant after adjusting for age, sex, educational level, smoking habit and alcohol intake.

\section{Discussion}

Prevalence of overweight and obesity found in this study are very similar to the ones found in surveys conducted in another rural population in Brazil ${ }^{20}$ and Nigeria ${ }^{21}$ and greater to those found in rural area of China ${ }^{22}$. Moreover, data from population surveys at national level with probability samples indicate an excess weight of $38.8 \%$ in men and $47.9 \%$ in women. Moreover, obesity has reached $16.5 \%$ in women and $8.8 \%$ in $\mathrm{men}^{7}$, which argues in favor of a potential representation of the studied rural population. The present study also revealed that obesity was more prevalent among women than men, which has been shown previously in the city of Cavunge, rural area of Bahia, Brazil ${ }^{23}$. Several factors may 
Table 1. Medians and interquartile range of blood pressure, anthropometric and biochemical characteristics of the study population according to sex. Virgem das Graças / Caju, 2004 - 2009.

\begin{tabular}{|c|c|c|c|c|}
\hline \multirow{3}{*}{ Variables } & \multicolumn{4}{|c|}{2004} \\
\hline & \multicolumn{2}{|c|}{ Men } & \multicolumn{2}{|c|}{ Women } \\
\hline & Median & IQR & Median & IQR \\
\hline $\mathrm{SBP}(\mathrm{mmHg})$ & $129.00^{*}$ & $119.00-143.33$ & 129.00 & $116.92-148.00$ \\
\hline DBP (mmHg) & 80.67 & $73.17-87.00$ & 81.17 & $72.00-91.00$ \\
\hline BMI $\left(\mathrm{kg} / \mathrm{m}^{2}\right)$ & $21.94^{*}$ & $20.34-23.78$ & 23.20 & $20.87-26.50$ \\
\hline $\mathrm{WC}(\mathrm{cm})$ & 79.73 & $75.08-85.35$ & 79.11 & $72.59-87.25$ \\
\hline Total cholesterol (mg/dl) & $184.00^{\star}$ & $149.00-213.75$ & 185.00 & $161.50-224.00$ \\
\hline LDL-C (mg/dl) & $115.00^{*}$ & $93.25-140.75$ & 114.00 & $92.50-141.50$ \\
\hline HDL-C (mg/dl) & 46.00 & $38.00-53.00$ & 47.00 & $40.00-56.50$ \\
\hline Triglyceride (mg/dl) & $79.50^{*}$ & $60.00-111.75$ & 98.00 & $67.00-126.50$ \\
\hline \multirow{3}{*}{ Variables } & \multicolumn{4}{|c|}{2009} \\
\hline & \multicolumn{2}{|c|}{ Men } & \multicolumn{2}{|c|}{ Women } \\
\hline & Median & IQR & Median & IQR \\
\hline $\mathrm{SBP}(\mathrm{mmHg})$ & $126.66^{\star}$ & $117.00-139.67$ & 127.67 & $111.16-143.33$ \\
\hline DBP (mmHg) & 80.00 & $75.33-89.33$ & 80.67 & $72.00-88.66$ \\
\hline BMI $\left(\mathrm{kg} / \mathrm{m}^{2}\right)$ & $22.46^{\star}$ & $20.71-25.01$ & $24.37^{\star}$ & $22.02-27.60$ \\
\hline $\mathrm{WC}(\mathrm{cm})$ & 80.93 & $75.78-88.37$ & 82.03 & $75.11-91.90$ \\
\hline Total cholesterol (mg/dl) & $197.50^{\star}$ & $162.50-221.00$ & 199.00 & $168.00-231.50$ \\
\hline LDL-C (mg/dl) & $125.00^{\star}$ & $100.50-145.50$ & 124.00 & $101.00-150.50$ \\
\hline HDL-C (mg/dl) & 50.00 & $38.00-59.00$ & $53.00^{\star}$ & $42.00-62.50$ \\
\hline Triglyceride $(\mathrm{mg} / \mathrm{dl})$ & 77.00 & $55.00-121.75$ & 80.00 & $58.00-121.25$ \\
\hline
\end{tabular}

${ }^{*} \mathrm{p}<0.05$ (Mann-Whitney test); BMI: Body Mass Index; DBP: Diastolic Blood Pressure; SBP: Systolic Blood Pressure; HDL-C: High-density lipoprotein cholesterol; LDL-C: Low-density lipoprotein cholesterol; WC: Waist Circumference; IQR: Interquartile Range.

Table 2. Mean changes and 95\% confidence intervals of anthropometric variables in the study population according to sex. Virgem das Graças / Caju, 2004 - 2009.

\begin{tabular}{|c|c|c|c|c|c|c|}
\hline \multirow{3}{*}{$\begin{array}{c}\text { Anthropometric } \\
\text { Changes }\end{array}$} & \multicolumn{4}{|c|}{ Sex } & \multirow{2}{*}{\multicolumn{2}{|c|}{ Total }} \\
\hline & \multicolumn{2}{|c|}{ Men } & \multicolumn{2}{|c|}{ Women } & & \\
\hline & Mean & $95 \% \mathrm{CI}$ & Mean & $95 \% \mathrm{CI}$ & Mean & $95 \% \mathrm{CI}$ \\
\hline Weight $(\mathrm{kg})$ & 1.87 & $1.27 ; 2.46$ & 2.88 & $2.14 ; 3.63$ & 2.40 & $1.91 ; 2.89$ \\
\hline BMI $\left(\mathrm{kg} / \mathrm{m}^{2}\right)$ & 0.75 & $0.53 ; 0.96$ & 1.27 & $0.96 ; 1.59$ & 1.02 & $0.82 ; 1.22$ \\
\hline $\mathrm{WC}(\mathrm{cm})$ & 1.81 & $1.16 ; 2.47$ & 3.19 & $2.22 ; 4.15$ & 2.53 & $1.93 ; 3.13$ \\
\hline
\end{tabular}

BMI: Body Mass Index; CI95\%: Confidence Interval 95\%; WC: Waist Circumference.

explain these findings: women accumulate more visceral and subcutaneous fat than men; differences in dietary patterns between sex; higher life expectancy of women; menopause is accompanied by weight gain and adiposity in women ${ }^{24,25}$.

In the five years we could observe the increase in total cholesterol and LDL-C, which may lead to an increased risk of developing cardiovascular diseases in these communities' population ${ }^{26}$. One potential explanation of this result might be the low consumption of fruits and vegetables in rural areas and access to these foods, since this is influenced by harvest periods and between crop which mainly affects the consumption of fruits ${ }^{27}$. Moreover, the climate where the dry predominates over the rainy season hampers the cultivation of land ${ }^{28}$ and justifies the difficulty of planting and production of vegetables. Noteworthy there is also the low income found among these populations $^{29}$. 
Table 3. Multivariate adjusted linear regression models with logarithm of lipid variables dependents according to category of BMI and WC changes - Virgem das Graças / Caju, 2004 - 2009.

\begin{tabular}{|c|c|c|c|c|c|c|c|c|}
\hline \multirow[t]{2}{*}{ Variables } & \multicolumn{2}{|c|}{$\begin{array}{c}\text { Total Cholesterol } \\
(\mathrm{mg} / \mathrm{dl})\end{array}$} & \multicolumn{2}{|c|}{$\begin{array}{l}\text { LDL-C } \\
(\mathrm{mg} / \mathrm{dl})\end{array}$} & \multicolumn{2}{|c|}{$\begin{array}{l}\text { LDL-C / HDL-C } \\
(\mathrm{mg} / \mathrm{dl})\end{array}$} & \multicolumn{2}{|c|}{$\begin{array}{l}\text { HDL-C } \\
(\mathrm{mg} / \mathrm{dl})\end{array}$} \\
\hline & $\beta$ & $95 \% \mathrm{CI}$ & $\beta$ & $95 \% \mathrm{CI}$ & $\beta$ & $95 \% \mathrm{CI}$ & $\beta$ & 95\% CI \\
\hline \multicolumn{9}{|c|}{ Body Mass Index Changes $\left(\mathrm{kg} / \mathrm{m}^{2}\right)$} \\
\hline Category1 (-20.0 to $0.0 \%)$ & Ref. & - & Ref. & - & Ref. & - & Ref. & - \\
\hline Category 2 (0.01 to $10.0 \%)$ & 0.04 & $-0.00 ; 0.08$ & 0.08 & $0.02 ; 0.14$ & 0.15 & $0.06 ; 0.25$ & -0.06 & $-0.12 ; 0.15$ \\
\hline Category 3 (> 10.0\%) & 0.04 & $-0.01 ; 0.09$ & 0.09 & $0.01 ; 0.16$ & 0.14 & $0.02 ; 0.25$ & -0.02 & $-0.11 ; 0.06$ \\
\hline \multicolumn{9}{|c|}{ Waist Circumference Changes (cm) } \\
\hline Category 1 ( -20.0 to $0.0 \%)$ & Ref. & - & Ref. & - & Ref. & - & Ref. & - \\
\hline Category 2 (0.01 to $10.0 \%)$ & -0.03 & $-0.07 ; 0.01$ & -0.03 & $-0.09 ; 0.03$ & -0.02 & $-0.11 ; 0.07$ & -0.02 & $-0.09 ; 0.05$ \\
\hline Category $3(>10.0 \%)$ & 0.03 & $-0.03 ; 0.09$ & 0.05 & $-0.04 ; 0.13$ & 0.07 & $-0.06 ; 0.19$ & -0.02 & $-0.11 ; 0.07$ \\
\hline
\end{tabular}

CI 95\% Confidence Interval 95\%; $\beta$ : beta coefficient; HDL-C: High-density lipoprotein cholesterol; LDL-C: Low-density lipoprotein cholesterol. BMI: Adjusted R² Total Cholesterol: 0.23 ; adjusted R² LDL-C: 0.12 ; adjusted R² LDL/HDL: 0.06; adjusted R²HDL: 0.08 ; Total Cholesterol alpha coefficient: 4.83; LDL-C alpha coefficient: 4.43; alpha coefficient LDL/HDL: 0.81 ; alpha coefficient HDL: 3.62 . WC: Adjusted R ${ }^{2}$ Total Cholesterol: 0.23; adjusted R ${ }^{2}$ LDL-C: 0.14; adjusted R ${ }^{2}$ LDL/HDL: 0.04; adjusted $\mathrm{R}^{2} \mathrm{HDL}: 0.08$; Total Cholesterol alpha coefficient: 4.88; LDL-C alpha coefficient: 4.46; alpha coefficient LDL/HDL: 0.89; alpha coefficient HDL: 3.61. Model adjusted for age, sex, educational level, smoking habit and alcohol intake.

Table 4. Multivariate linear regression models with logarithm of blood pressure variables according to category of BMI and WC changes. Virgem das Graças / Caju, 2004 - 2009.

\begin{tabular}{|c|c|c|c|c|}
\hline \multirow{2}{*}{ Variables } & \multicolumn{2}{|c|}{ SBP (mmHg) } & \multicolumn{2}{|r|}{$\mathrm{DBP}(\mathrm{mmHg})$} \\
\hline & $\beta$ & $95 \% \mathrm{CI}$ & $\beta$ & $95 \% \mathrm{CI}$ \\
\hline \multicolumn{5}{|l|}{ Body Mass Index Changes $\left(\mathrm{kg} / \mathrm{m}^{2}\right)$} \\
\hline Category $1(-20.0$ to $0.00 \%)$ & Ref. & - & Ref. & - \\
\hline Category $2(0.01 \%$ to $10.0 \%)$ & 0.01 & $-0.02 ; 0.04$ & 0.02 & $-0.01 ; 0.05$ \\
\hline Category $3(>10.0 \%)$ & 0.03 & $-0.01 ; 0.07$ & 0.07 & $0.03 ; 0.11$ \\
\hline \multicolumn{5}{|l|}{ Waist Circumference Changes $(\mathrm{cm})$} \\
\hline Categoryl (-20.0 to $0.00 \%)$ & Ref. & - & Ref. & - \\
\hline Category $2(0.01 \%$ to $10.0 \%)$ & 0.02 & $-0.01 ; 0.05$ & 0.03 & $-0.00 ; 0.06$ \\
\hline Category $3(>10.0 \%)$ & 0.06 & $0.02 ; 0.10$ & 0.09 & $0.04 ; 0.13$ \\
\hline
\end{tabular}

CI95\%: Confidence Interval 95\%; DBP: Diastolic Blood Pressure; SBP: Systolic Blood Pressure. BMI: Adjusted R² SBP: 0.12; R² adjusted DBP: 0.12; SBP alpha coefficient: 4.74; DBP alpha coefficient: 4.32. WC: Adjusted R² SBP: 0.15; R² adjusted DBP: 0.13; SBP alpha coefficient: 4.75; DBP alpha coefficient: 4.32. Model adjusted for age, sex, educational level, smoking habit and alcohol intake.

Regarding the prevalence of hypertension, our results indicate this is public health problem in the studied population, although we have observed the reduction of blood pressure levels in the five years of study. This decrease might be explained by the Family Health Program (FHP) interventions in these communities, providing diagnose, medication and monitoring of hypertension.

The main finding of this study was that participants who had positive changes of BMI between 2004 and 2009 also showed significant increased levels of LDL-C, LDL/HDL ratio and DBP, when compared with those who lost BMI units. These associations remained significant even after adjusting for confounding variables. These findings are similar to those found by the Canadian Heart Health Surveys Research Group ${ }^{30}$.To our knowledge there are no longitudinal studies that show a positive relationship between adiposity increase and increased levels of cardiometabolic risk factors such as LDL-C, HDL-C, LDL/HDL ratio and levels of systolic and diastolic pressure in rural populations in Brazil.

In this study, it was observed a mean increase of $1.02 \mathrm{~kg} / \mathrm{m}^{2}$ BMI units in the population over the course of the studied period. Previous research has shown that weight gain in the long 
run increases blood pressure considerably and estimates from the Framingham study suggest that about $70 \%$ of new cases of hypertension could be attributed to weight gain ${ }^{31}$. According to the Nurses' Health Study, positive changes in BMI of $1 \mathrm{~kg} / \mathrm{m}^{2}$ were associated with a $12 \%$ increase of risk of hypertension ${ }^{32}$. Similar results were also found elsewhere, indicating a positive relationship between BMI and increased blood pressure $^{33,34}$. Finally, the Coronary Artery Risk Development in Adults study (CARDIA), conducted between 1985 and 1986, involving 5,115 subjects of both sex, have shown a strong association between obesity and increased blood pressure levels ${ }^{35}$. We found no significant associations between increased adiposity and total cholesterol, HDL-C and SBP. This may have occurred due to our small sample size.

Regarding the waist circumference positive changes in five years, our findings have shown no association with lipid outcomes, but with blood pressure increased levels, suggesting that total body fat seems to be more relevant in relation to these variables (LDL-C and LDL / HDL) than the central fat. Previous studies have reported that individuals with abdominal obesity have a higher prevalence of hypertension and dyslipidemia compared to those who did not have excess abdominal fat, consequently, increased risk of developing cardiovascular disease $\mathrm{e}^{36,37}$.

The main limitation of this study is related to the external validity of these results, which should be interpreted with caution, because the studied rural areas may not be a representative sample of the rural population in Brazil. In addition, our multivariate models were not adjusted for the use of lipid-lowering drugs, since this information was not available. Despite this limitation, an interesting strength in this study was the collection of anthropometric and blood pressure measurements using appropriate techniques by reliable and rigorously trained interviewers, and based on international guidelines, rather than by self-reference. The second strength was the exposure variables measured at two points in five years to the follow-up design. The third is the more realistic prevalence found in this population, because they rely on direct measurements, justifying higher hypertension frequency and hypercholesterolemia. Despite the importance of race as a risk factor for hypertension, this information was not included in this study, because this specific variable may have been misclassified due to high miscegenation of the Brazilian population. Ethnic and racial data must be treated with caution considering the varying circumstances under which they are collected. In addition, the use of race information may reflect culture, social norms and traditions rather than genetic or hereditary origins ${ }^{38}$.

The scenario found in the studied rural population may contribute greatly to high levels of lost of disability-adjusted life years and thus to premature deaths, loss of quality of life, high degree of limitation of people in their work and leisure activities, and thus, cause negative economic impacts on families, communities and society as a whole ${ }^{39}$. Finally, the results of this study can potentially provide a substantial dimension of chronic diseases in the Brazilian rural population.

In conclusion, we observed that increased of BMI over the course of five years was an important predictor of lipid and blood pressure levels. The increased of WC was predictor of blood pressure levels among residents in rural areas in Brazil. Such findings confirm that BMI and WC positive changes may be a valuable predictor of metabolic disorders and changes in blood pressure in the evaluated rural population, even after adjustments for confounding variables.

It is therefore necessary that the health sector authorities urgently adopt measures for the treatment, control and prevention of hypertension, dyslipidemia and obesity, in order to reduce the incidence of incapacitating and lethal cardiovascular diseases among the rural population.

These results may also contribute to the recognition that promoting cardiovascular health remains unsettled in rural areas and the implementation of the recently proposed strategic action plan goals for the non-communicable chronic diseases in Brazil 2011-2022, by the Ministry of Health is incipient in these settings. Another strategy implemented by the Ministry of Health that urges to be provided in rural areas are the Academia da Cidade Programs, which aims to offer physical activity, healthy eating and health education promotion among the general population, located in squares, parks and sports complexes in main Brazilian cities. In sum, public health policies should be a priority for these populations that would benefit greatly from health promotion and prevention strategies. 


\section{Collaborations}

T Géa-Horta and G Velasquez-Melendez planned the study, analyzed the data, interpreted the results and wrote and reviewed the manuscript. MA Beinner, A Gazzinelli and MSF Mendes revised the manuscript. All the authors read and approved the final manuscript.

\section{Acknowledgments}

This study was supported by a grant from Fundação de Apoio à Pesquisa do Estado de Minas Gerais (FAPEMIG). G Velasquez-Melendez and A Gazzinelli are research fellows from the Brazilian National Council of Research and Technology (CNPq).

\section{References}

1. Finucane MM, Stevens GA, Cowan MJ, Danaei G, Lin JK, Paciorek CJ, Singh GM, Gutierrez HR, Lu Y, Bahalim AN, Farzadfar F, Riley LM, Ezzati M. National, regional, and global trends in body-mass index since 1980: systematic analysis of health examination surveys an epidemiological studies with 960 country-years and 9.1 million participants. Lancet 2011; 377(9765):557567.

2. World Health Organization (WHO). Health topics [computer program]. 2007. [cited 2015 Mar 23]. Available on: http://www.who.int/topics/obesity/en

3. Prospective Studies Collaboration, Whitlock G, Lewington S, Sherliker P, Clarke R, Emberson J, Halsey J, Qizilbash N, Collins R, Peto R. Body-mass index and cause-specific mortality in 900000 adults: collaborative analyses of 57 prospective studies. Lancet 2009; 373(9669):1083-1096.

4. Yuan X, Zhuo Z, Wang J, Liu X, Lü M, Xu J. Relationship between the body mass index, waist circumference and lipids levels among adults in Shenzhen. Wei Sheng Yan Jiи 2013; 42(3):360-S363.

5. Scarsella C, Després JP. Tratamiento de la obesidad: necesidad de centrar la atención en los pacientes de alto riesgo caracterizados por la obesidad abdominal. Cad Saude Publica 2003; 19(Supl. 1):S7-S19.

6. Snowdon W, Malakellis M, Millar L, Swinburn B. Ability of body mass index and waist circumference to identify risk factors for non-communicable disease in the Pacific Islands. Obes Res Clin Pract 2014; 8(1):e36-e45.

7. Instituto Brasileiro de Geografia e Estatística (IBGE). Pesquisa de orçamentos familiares 2008-2009: análise da disponibilidade domiciliar de alimentos e do estado $n u-$ tricional no Brasil. Rio de Janeiro: IBGE; 2010.

8. Mondini L, Monteiro CA. Mudanças no padrão de alimentação na população urbana brasileira (1962-1988). Rev Saude Publica 1997; 28:433-439

9. Martins JS. O futuro da sociologia rural e sua contribuição para a qualidade de vida rural. Estud Av 2001; 15(43):31-36.

10. Silva DA, Felisbino-Mendes MS, Pimenta AM, Gazzinelli A, Kac G, Velásquez-Meléndez G. Distúrbios metabólicos e adiposidade em uma população rural. Arq Bras Endocrinol Metab 2008; 52(3):489-498.

11. Felisbino-Mendes MS, Jansen AK, Gomes CS, Velásquez-Meléndez G. Avaliação dos fatores de risco cardiovasculares em uma população rural brasileira. Cad Saude Publica 2014; 30(6):1183-1194.

12. Kassouf AL. Acesso aos serviços de saúde nas áreas urbana e rural do Brasil. Rev. Econ. Sociol. Rural 2005; 43(1):29-44.

13. Organização Pan-Americana da Saúde (OPAS). Doenças crônico degenerativas e obesidade: estratégia mundial sobre alimentação saudável, atividade física e saúde. Brasília: Formatos Design; 2003.

14. Lohman TG, Roche AF, Martorell R. Anthropometric standardization reference manual. Champaign: Human Kinetics Books; 1988. 
15. World Health Organization (WHO). Physical status: the use and interpretation of anthropometry. Geneva: WHO; 1995.

16. World Health Organization (WHO). Obesity: preventing and managing the global epidemic. Geneva: WHO; 1998.

17. Friedewald WT, Levy RI, Frederickson DS. Estimation of concentrations of low-density cholesterol in plasma, without use of the preparative ultracentrifuge. Clin Chem 1972; 18(6):499-502.

18. U.S. Department of Health and Human Services. National Institutes of Health National Heart, Lung, and Blood Institute. National High Blood Pressure Education Program. The seventh report of the Joint National Committee on prevention, detection, evaluation, and treatment of high blood pressure. Hypertension 2003; 157:2413-2446.

19. Brasil. Resolução no 196 , de 10 de outubro de 1996. Diretrizes e normas regulamentadoras de pesquisas envolvendo seres humanos. Diário Oficial da União 1996; 11 out.

20. Soares DA, Barreto SM. Sobrepeso e obesidade abdominal em adultos quilombolas, Bahia, Brasil. Cad Saude Publica 2014; 30(2):341-354.

21. Adebayo RA, Balogun MO, Adedoyin RA, ObashoroJohn OA, Bisiriyu LA, Abiodun OO. Prevalence and pattern of overweight and obesity in three rural communities in southwest Nigeria. Diabetes Metab Syndr Obes 2014; 7:153-158.

22. Zhang X, Sun Z, Zhang X, Zheng L, Liu S, Xu C, Li J, Zhao F, Li J, Hu D, Sun Y. Prevalence and associated factors of overweight and obesity in a Chinese rural population. Obesity 2008; 16(1):168-171.

23. Matos AC, Ladeia AM. Assessment of cardiovascular risk factors in rural community in the Brazilian state of Bahia. Arq Bras Cardiol 2003; 81(3):297-302

24. Despres JP. Body Fat Distribution and Risk of Cardiovascular Disease An Update. Circulation 2012; 126(10):1301-1313.

25. Palmer BF, Clegg DJ. The sexual dimorphism of obesity. Mol Cell Endocrinol 2015; 402:113-119.

26. Lamarche B, Tchernof A, Mauriege P, Cantin B, Dagenais GR, Lupien PJ, Després JP. Fasting insulin and apolipoprotein B levels and low-density lipoprotein particle size as risk factors for ischemic heart disease. JAMA 1998; 279(24):1955-1961

27. Carvalho EO, Rocha EF. Consumo alimentar de população adulta residente em área rural da cidade de Ibatiba (ES, Brasil). Cien Saude Colet 2011; 16(1):179-185.

28. Brasil. Ministério da Saúde (MS). Diagnóstico de saúde e nutrição da população do campo: levantamento de dados. Brasília: MS; 2004.

29. Claro RM, Monteiro CA. Family income, food prices, and household purchases of fruits and vegetables in Brazil. Rev Saude Publica 2010; 44(6):1-6.
30. Macdonald SM, Reeder BA, Chen Y, Després JP. Obesity in Canada: a descriptive analysis. Canadian Heart Health Surveys Research Group. CMAJ 1997; 157(Supl. 1):S3-S9.

31. Hubert HB, Feinleib M, McNamara PM, Castelli WP. Obesity as an independent risk factor for cardiovascular disease: a 26-year follow-up of participants in the Framingham Heart Study. Circulation 1983; 67(5):968977.

32. Huang Z, Willett WC, Manson JE, Rosner B, Stampfer MJ, Speizer FE, Colditz GA. Body weight, weight change, and risk for hypertension in women. Ann Intern Med 1998; 128(2):81-88.

33. Dua S, Bhuker M, Sharma P, Dhall M, Kapoor S. Body mass index relates to blood pressure among adults. North Am J Med Sci 2014; 6(2):89-95.

34. Tsujimoto T, Sairenchi T, Iso H, Irie F, Yamagishi K, Tanaka K, Muto T, Ota H. Impact of obesity on incident hypertension independent of weight gain among nonhypertensive Japanese: the Ibaraki Prefectural Health Study (IPHS). J Hypertens 2012; 30(6):1122-1128.

35. Dyer AR, Liu K, Walsh M, Kiefe C, Jacobs DR Jr, Bild DE. Ten-year incidence of elevated blood pressure and its predictors: the CARDIA study. Coronary Artery Risk Development I (Young) Adults. J Hum Hypertens 1999; 13(1):13-21.

36. Velásquez-Meléndez G, Kac G, Valente JG, Tavares R, Silva CQ, Garcia ES. Evaluation of waist circumference to predict general obesity and arterial hypertension in women in Greater Metropolitan Belo Horizonte, Brazil. Cad Saude Publica 2002; 18(3):765-771.

37. Després JP, Lemieux I, Prud'homme D. Treatment of obesity: need to focus on high risk abdominally obese patients. BMJ 2011; 322(7288):716-720.

38. Muniz JO. Sobre o uso da variável raça-cor em estudos quantitativos. Rev. Sociol. Polit. 2010; 18(36):277-291.

39. Brasil. Ministério da Saúde (MS). Plano de ações estratégicas para o enfrentamento das doenças crônicas não transmissiveis (DCNT) no Brasil 2011-2022. Brasília: MS; 2011. [Série B. Textos Básicos de Saúde].

Artigo apresentado em 07/04/2016

Aprovado em 17/08/2016

Versão final apresentada em 19/08/2016 